\title{
Onde está o sujeito pós-colonial? (Algumas reflexões sobre o espaço e a condição pós-colonial na literatura angolana)
}

\author{
Simone Pereira Schmidt \\ (Universidade Federal de Santa Catarina)
}

RESUMO

Tomando por objeto algumas narrativas do chamado "espaço-tempo da língua portuguesa", em especial narrativas angolanas, o foco da discussão está orientado para a representação dos sujeitos que se encontram situados numa experiência pós-colonial, dentro de seus contextos geográficos e históricos específicos.

PALAVRAS-CHAVE: pós-colonialismo, sujeito, lugar.

\section{ABSTRACT:}

This article focuses on the representation of postcolonial subject in Angolan literature. Concerned about concepts like place and postcolonial experience, the paper intends to investigate the postcolonial subject situated in his specific geographic and historical context.

KEYWORDS: postcolonialism; subject; place. 


\section{"Careço de um lugar para esperar, sem tempo, sem mim."}

Mia Couto

Dentre as inúmeras teorias que se dedicam a pensar as questões contemporâneas, um corpo de estudos se destaca particularmente quando nos voltamos para o contexto africano: os estudos pós-coloniais, em seu empreendimento de contestação da dominação colonial e dos legados do colonialismo. Pois se há um conceito necessário a partir do qual devemos interpelar as manifestações culturais da África - particularmente dos países de língua portuguesa, que muito recentemente vieram a se configurar como nações independentes -, este certamente é o conceito de pós-colonial. Embora seja extremamente amplo e polissêmico, ele nos permite entrever as profundas implicações históricas, políticas e culturais da questão que traz ao debate. Bill Ashcroft, Gareth Griffiths e Helen Tiffin (2005, p. 186) fazem um breve histórico do conceito, esclarecendo que ele foi originalmente empregado pelos historiadores no Pós-Guerra com um sentido claramente cronológico, para designar o momento forte da descolonização que então se iniciava. "Póscolonial" tinha, portanto, o sentido estrito de designar o processo de independência dos países que haviam sido colonizados pela Europa. Contudo, a partir dos anos 70, o termo passa a ser empregado por críticos literários para discutir os diversos efeitos da colonização. Nesse momento, os autores destacam a importância dos trabalhos pioneiros de Edward Said, Gayatri Spivak e Homi Bhabha.

A partir dessas primeiras formulações teóricas sobre o poder da representação colonial, o conceito se alarga para significar uma ampla gama de experiências políticas, culturais e subjetivas, que se deslocam no tempo (pré e pós-colonial) e se situam em diferentes lugares. Há hoje uma pluralidade muito heterogênea de posições subjetivas, lugares geográficos, pontos de vista teóricos e políticos e empreendimentos críticos, a partir dos quais o póscolonial pode ser pensado. Se a heterogeneidade do conceito se mostra como um risco sempre presente de suscitar divergências incontornáveis, por outro lado, torna mais rico o seu debate e aviva seu potencial epistemológico e político. A definição de Boaventura de Sousa Santos torna mais claro este potencial; segundo o sociólogo português, o pós-colonialismo consiste num conjunto de correntes teóricas "que têm em comum darem primazia teórica e política às relações desiguais entre o Norte e o Sul na explicação ou na compreensão do mundo contemporâneo" (2004, p. 8). Essas relações desiguais, sendo fruto do colonialismo enquanto projeto político central do Ocidente moderno, permanecem como rastro de tensões nos campos de poder e saber (Hall, 2003, p. 119), que persistem muito além do fim do colonialismo como instituição política.

Assim, o pós-colonial, saltando sobre o limite cronológico estreito (segundo o qual estaria preso ao prefixo "pós", que rigorosamente lhe assinalaria o significado exclusivo daquilo que vem "depois" da colonização), pode ser compreendido, de maneira mais ampla, como uma arena, onde os diferentes elementos das culturas estabelecem entre si relações de poder, tal como podemos depreender da formulação de Stuart Hall: "Os momentos de independência e pós-colonial, nos quais [as] histórias imperiais continuam a ser vivamente retrabalhadas, são necessariamente, portanto, momentos de luta cultural, de revisão e de reapropriação" (Hall, 2003, p. 34).

Se pensarmos o pós-colonial dentro de uma espécie de programa de contestação e releitura crítica do legado cultural do colonialismo, podemos nos valer das ideias de Jorge de Alva (apud Loomba, 1998, p. 12), para quem o póscolonialismo deve significar não tanto uma subjetividade "depois" da 
experiência colonial, mas uma subjetividade em oposição aos discursos e práticas imperializantes e colonizadoras. Tal proposição se baseia no pressuposto de que não há uma progressão histórica linear, mas uma multiplicidade de narrativas paralelas e muitas vezes em conflito. No mesmo sentido, Ania Loomba (1998, p. 18-19) observa que o pós-colonialismo se dedica a investigar como ambos os lados da relação colonial, a metrópole e a colônia, sofreram profundas alterações através do processo colonial, embora isso não signifique que eles viveram essa experiência da mesma maneira. O que se pode entender de sua afirmação é que o pós-colonial é, necessariamente, relacional, mas não se devem obscurecer, através dessa relacionalidade, as profundas desigualdades que nele estão implicadas.

Se uma multiplicidade de posições - geográfica, cultural, histórica, subjetiva - pode ser designada pelo conceito de pós-colonial, deriva daí uma preocupação que deve ser central neste debate: onde fica o pós-colonial? Perguntas semelhantes vêm sendo formuladas pela crítica, mas me parece que a indagação acerca do lugar da experiência pós-colonial assume, no contexto da língua portuguesa, importância fundamental. Primeiramente em função da grande dispersão territorial da colonização portuguesa, aliada ao enfraquecimento crescente e ao modo persistente e anacrônico com que se manteve até meados dos anos 70 (no caso africano), o que veio a resultar em uma territorialidade advinda da experiência colonial muito peculiar: dispersa em muitas e distantes regiões do planeta, historicamente isoladas entre si, e, contudo, partilhando traços históricos e culturais comuns.

Uma segunda explicação para o grande interesse que a questão do lugar suscita no caso das ex-colônias portuguesas advém da necessidade que sentimos, ao entrar em contato com toda uma ampla bibliografia de língua inglesa, que investiga prioritariamente o colonialismo inglês e sua repercussão, de empreender uma tarefa de tradução do conceito para o universo mais específico dos territórios de língua portuguesa. Quando me refiro à tradução, não estou falando daquele óbvio procedimento de tradução linguística, necessário para a compreensão do texto estrangeiro. Estou, sim, referindo-me a uma reordenação dos temas locais/globais na perspectiva da tradução cultural. A prática tradutória que estou propondo busca, através do estabelecimento de uma via dialógica não provinciana e anticolonial, trazer os temas para o debate localizado. Ou seja, sua proposição é romper o sentido único de um pensamento que vem do norte e interpreta o sul (sendo que, aqui, sul e norte possuem sentidos políticos e simbólicos, mais até do que geográficos), e propor a reinterpretação, numa perspectiva situada e contrahegemônica (mas sem xenofobia) dos temas propostos pelos textos norteadores do debate pós-colonial. $O$ que a prática tradutória afirma, portanto, é a viabilidade de um saber globalizado e ao mesmo tempo situado, teoricamente bem instrumentalizado, mas contra-hegemônico, ou anticolonial.

Ao refletir sobre sua condição de imigrante nos Estados Unidos, entrelaçando sua experiência com as experiências de outras imigrantes, pertencentes a outras etnias e herdeiras de outras histórias, a iraquiana Ella Shohat (2002, p. 101-102) observa que o relato das memórias das imigrantes nos EUA tem sido sempre contraposto a uma norma dominante branca e ocidental. Em lugar desta prática de "contra-falar" ou "contra-escrever", em que se revezam as não-ocidentais em oposição à norma ocidental dominante, Shohat propõe uma estratégia de horizontalidade, de não-verticalidade, ou, como ela esclareceu numa entrevista concedida em 2001, trata-se de ressignificar a ideia de relacionalidade, ou seja: mais do que enfocar 
comunidades em resistência contra um centro dominante (o que é ainda uma forma de privilegiar o centro, pelo menos como antagonista), o que se procura é "estender laços horizontais e verticais, entrelaçando comunidades e histórias em uma rede conflituosa" (Shohat, 2001, p. 158). Este princípio da horizontalidade, da não-centralidade, é o que de melhor podemos colher da prática tradutória. Assim, o que estou propondo é uma reflexão sobre a necessária tradução do conceito "pós-colonial" para o português, remetendo todo um conjunto de formulações, cuja origem tem sede no mundo anglosaxão, para o território geopolítico e simbólico da experiência colonial e póscolonial em português. Tal prática tem, necessariamente, muito a ver com a questão do lugar, pois, como formulou Edward Said, as histórias pós-coloniais precisam ser interpretadas como "uma rede de histórias interdependentes", "entrelaçadas e sobrepostas" (Said, 1995, p. 50-51), e a herança colonial deve ser revista como coexistência e combate de "geografias, narrativas e histórias rivais" (p. 22).

Sendo o pós-colonial, como já vimos, um conceito que remete a uma multiplicidade de posições (geográfica, cultural, histórica, subjetiva), perguntarmos onde está o pós-colonial no contexto das literaturas africanas de língua portuguesa nos leva a indagar quem é o sujeito pós-colonial nessas sociedades e qual o seu lugar, onde está representado e localizado. Tal pergunta reivindica o lugar concreto, o referencial histórico e político do conceito, que combate o risco da diluição do sujeito pós-colonial num alargamento demasiadamente amplo do significado de sua experiência, alargamento que no limite abrangeria, genericamente, a humanidade inteira. Ania Loomba alerta para o fato de que, se não for situado e localizado, o sujeito pós-colonial pode vir a se encontrar numa condição excessivamente vaga, e observa que nem todas as práticas e discursos de subordinação são iguais em qualquer época ou lugar (Loomba, 1998, p. 16-18).

Em síntese, seria empobrecedor e arriscado tentar homogeneizar a experiência pós-colonial, já que ela é, por princípio, heterogênea. Não podemos falar de um sujeito pós-colonial, pois sua identidade resulta da interseção de diversas faces de sua história e de seu presente, que dizem respeito à classe social em que se situa, ao país e à região de onde vem e onde está, à sua posição de gênero, raça e etnia, etc., sendo que todos esses elementos só podem ser vistos em sua complexa rede, densa de historicidade e múltipla em suas localizações.

Levando em conta a importância do debate em torno do lugar do sujeito pós-colonial, e procurando dar contornos mais visíveis a esta questão, proponho-me a construir uma breve cartografia da experiência pós-colonial nos países africanos de língua portuguesa, tomando por base a leitura de alguns textos literários em que a experiência pós-colonial se mostra claramente configurada. A partir da leitura dos textos, pretendo discutir brevemente a localização - espacial, concreta, histórica, mas também simbólica e subjetiva da experiência pós-colonial.

Nosso percurso inicia na Luanda colonial de Luandino Vieira, tal como a encontramos representada num conto datado de 1955, "A fronteira de asfalto" (Vieira, 2007, p. 37-44). Neste conto, a cidade atravessada pela "fronteira de asfalto" assinala o convívio tenso e conflituoso de colonizados e colonizadores. Neste embate, a questão racial é preponderante; Ricardo, o protagonista, acaba por pagar com a própria vida seu desejo ousado de amar uma menina branca. A separação racial é visível na cartografia da cidade, intensamente dividida entre as casas, os quintais, as ruas asfaltadas e os passeios floridos dos brancos, e as ruas sinuosas e de areia, "as casas de pau-a- 
pique à sombra de mulembas": "A casa dele ficava ao fundo. Via-se do sítio donde estava. Amarela. Duas portas, três janelas. Um cercado de aduelas e arcos de barril" (Vieira, 2007, p. 40). Se a situação colonial se encontra claramente configurada, sem sinais visíveis de mudança, no entanto, podemos encontrar na obstinação de Ricardo por entender as razões da forçada separação entre ele e sua amiga, os sinais de um descontentamento que são já um prenúncio de uma atitude anticolonial. Acuado pelo policial que o interpela na escuridão do quintal de sua amiga, ele sente medo, "o medo do negro pelo polícia", mas nem assim se detém: "Saltou o muro. Bateu no passeio com violência abafada pelos sapatos de borracha. Mas os pés escorregaram quando fazia o salto para atravessar a rua. Caiu e a cabeça bateu pesadamente de encontro à aresta do passeio" (Vieira, 2007, p. 43-44). No desfecho da narrativa, encontramos a reafirmação da desigualdade brutal que, situada no espaço tensamente desigual da cidade dividida entre brancos e negros, vitima e pune a transgressão do personagem, ao cruzar a "fronteira de asfalto".

Uma situação ainda colonial, mas já iluminada por fortes tons de um otimismo libertário, encontramos em "Estória da galinha e do ovo" (Vieira, 2004, p. 125-152), conhecido conto de Luandino Vieira, de 1963. Neste conto, inteiramente situado "nesta nossa terra de Luanda", como informa o autor ao final da narrativa (p. 152), o espaço onde transcorre a ação é o burburinho intenso e vibrante dos musseques na periferia de Luanda. Ali transcorre a maka que envolve toda a vizinhança, ou melhor: as mulheres da vizinhança. Pois o caso sobre uma galinha e um ovo, e a discussão interminável sobre a quem pertencem uma e outro, é, antes de mais nada, um assunto das mulheres. São elas que assumirão o protagonismo da ação inteira do conto. Um dado muito interessante - inclusive para um olhar mais atento à questão do gênero dentro da narrativa - é que as mulheres convocam, para resolver sua querela, a autoridade masculina, recorrendo, sucessivamente, às figuras do branco dono da quitanda, do religioso, do proprietário do musseque, do guarda-livros. Todas essas figuras - culminando com a intervenção violenta dos homens da polícia - resultam em grande frustração na solução do problema da galinha e do ovo. Fato que aponta para o mais rico elemento do jogo narrativo: a constatação lentamente construída - sobre o pano de fundo vivo do musseque e de sua vida cotidiana, seus embates, suas dificuldades, mas também suas alegrias e grandezas - de que são as mulheres (e as crianças, e a galinha, que, triunfante, levanta voo diante de seu espantado e maravilhado público no final da narrativa) as autoras de um futuro que se pode antever, no enfrentamento que protagonizam, afastando de si as figuras de mando, poder e engano simbolizadas pelos homens cujo conselho inicialmente solicitam. O conto pode ser assim interpretado como uma alegoria da trajetória desde a ingenuidade até a consciência, desde o conflito frágil até a sabedoria construída no enfrentamento dos poderosos e na solidariedade dos fracos. O musseque, neste percurso, representa algo muito maior do que o simples espaço onde a ação transcorre, pois, uma vez que ele constitui o laço identitário que vincula a experiência de todas as mulheres que protagonizam a ação, podemos afirmar que ele é protagonista também, anunciando em tons fortes (que encontram, aliás, uma significativa representação nas cores do céu, à medida que a tarde avança e o pôr-do-sol se aproxima) o desejo e o esforço de superação da situação colonial.

Encontramos a cidade de Luanda em sua feição abertamente póscolonial, no relato celebratório, e também crítico, dos pequenos contos entrelaçados pela figura de um cão, que transita entre as narrativas em $O$ cão $e$ os caluandas, de Pepetela (2002). Toda a geografia da cidade se mostra 
percorrida pelos tipos humanos que descrevem seus dramas, em tom anedótico ou lírico, ligados às vivências do país recém-independente. É assim que encontramos Tico, o poeta, perambulando pelas ruas da cidade, desempregado e satisfeito, acompanhado do cão com quem trava amizade. Percebendo-se num lugar privilegiado, de rapaz urbano cuja mãe está a ganhar razoavelmente bem como quitandeira, num momento de escassez de produtos e de serviços, Tico desfruta de seu ócio enquanto se considera um "intelectual revolucionário" sem ocupação. $O$ tom de seu discurso, como narradorpersonagem que descreve o momento histórico em que se encontra, é marcado pelo jargão marxista que então dominava o clima político da época. Com ironia, o personagem comenta que

Agora, com a abolição das classes sociais, ao que diziam, não havia mais diferenças. Por isso mesmo um patrício podia ter um cão desses, que dantes só os brancos e polícias podiam ter. Porque o patrício tinha enriquecido? Não, mas porque o cão se tinha proletarizado. Recordei uma passagem de Marx lida no jornal: sociedade de proletários. O cão, que nos tempos era burguês, tinha virado proleta (Pepetela, 2002, p. 15)

Se o rapaz considera, em sua alegre despreocupação, que agora "não havia mais diferenças", em outros contos do livro percebemos a preocupação do autor em revelar perspectivas mais sombrias e preocupantes do país em construção. É o caso, por exemplo, das tensões raciais que predominam na cena pós-colonial angolana, e que estão bem representadas num conto como "Entre judeus" (Pepetela, 2002, p. 131-138). Neste relato, a prostituta com quem o personagem-narrador se envolve numa noite de encontro num bar, assim se refere à questão racial:

- Lá no Brasil não sei como é. Mas aqui nós os dois temos uma coisa em comum. A cor, sabes? Mulato é o judeu de Angola. (...) Os judeus sempre foram os tipos que levaram de todos. Aqui é o mulato. Se alguma coisa corre mal, a culpa é do mulato que estiver mais perto. Porque os negros têm a sua tribo, as suas grandes famílias, defendem-se. Mulato não tem tribo (Pepetela, 2002, p. 132).

Como vemos, o autor toca numa ferida importante da situação póscolonial, algo que se mostra como um problema dentre os muitos que o novo país tem de enfrentar em sua construção. Se no tempo colonial a tensão racial estava muito claramente delineada na "fronteira de asfalto" que segregava os negros e demarcava violentamente o poder dos brancos, o legado dessas tensões, especialmente configurada na questão da mestiçagem, tão presente na sociedade angolana, se mostra como um tema complexo, e que produz novas desigualdades nas relações entre os sujeitos pós-coloniais. Sujeito quase branco, a lembrar, com os traços de seu próprio corpo, a permanência do tempo colonial, o mulato é um sujeito "sem tribo", espécie de "judeu errante" em busca de um lugar no conjunto das novas relações que se estabelecem no país liberto do jugo colonial. Esse e outros problemas são abordados pelo autor nos breves relatos de $O$ cão e os caluandas.

Um tom igualmente crítico, embora também celebratório e eivado de humor, é o que encontramos nas memórias do menino Ndalu, que, no romance Bom dia camaradas (Ondjaki, 2003) nos relata suas memórias de uma infância vivida na Luanda pós-independência. É pelo relato afetivo do 
personagem-narrador - que, ao recordar o passado, nos oferece o olhar ingênuo e encantado com que então percebia o mundo à sua volta - que vamos tomando contato com os fatos vividos nessa época. Pela voz do narrador, os eventos todos daquele tempo são contados com a graça de um jogo de meninos: as tardes na escola, o convívio com a família, as celebrações cívicas, a doutrinação do partido, as grandes confusões, o medo da violência... Nos diálogos vivos, e quase sempre engraçados, que se desenrolam entre as crianças, ou entre elas e os mais-velhos, a grande personagem resulta ser a Angola pós-colonial e, de forma mais concreta, a Luanda do período, onde se desenrolam as piadas e onde se deixam entrever, embora de forma apenas sugerida, os grandes conflitos a serem enfrentados pelo país. Exemplo disso encontramos numa sequência de ações que transcorrem durante um passeio que o menino Ndalu realiza com sua tia, recém-chegada de Portugal, onde mora há muitos anos, e portanto desabituada dos códigos de conduta locais. Neste passeio, em que o menino se orgulha de mostrar sua cidade à tia, ocorrem alguns incidentes reveladores, como a passagem da comitiva presidencial, e o constrangimento provocado pelo desconhecimento da tia em relação à conduta exigida em presença do "camarada presidente":

-Tia, tia! Tens que sair do carro, rápido.

- Mas sair do carro porquê? Eu não quero fazer chichi! - ela estava mesmo sentada, impressionante, e ainda estava a rir.

- Mas isto não é para fazer chichi, tia, tens que sair do carro e ficar paradinha aí fora, aqueles carros pretos são do camarada presidente.

- Ó filho, não é preciso, ele vai passar do outro lado.

-Dona Eduarda, por favor, sai só do carro... - o camarada João falava tipo tava com febre.

-Tia, a sério, sai do carro agora! - quase gritei.

(Ondjaki, 2003, p. 53).

Se percebemos ao longo da narrativa a presença de um tom crítico, que denuncia, tal como vemos na cena apresentada acima, os desmandos e equívocos do poder recém instituído, a nota emocional que domina o discurso do narrador, contudo, é fortemente afetiva, resultando em simpatia e profunda adesão à cidade e ao país em que sua memória tem lugar.

Tanto em Bom dia camaradas como em $O$ cão $e$ os caluandas, encontramos um olhar retrospectivo que procurar reler, de forma simultaneamente crítica e afetiva, o projeto de país que então se desenhava, num movimento de constante deslizamento entre a adesão e a não-adesão a suas iniciativas. Os sujeitos pós-coloniais, nestas narrativas, já claramente configurados, investem na invenção de um país através da narrativa de seu cotidiano, com suas dores e delícias. Como sabemos a partir de autores como Benedict Anderson (2008), Eric Hobsbawm (2000) e Edward Said (1995), as próprias nações são narrativas, e o poder de narrar (ou de impedir que se narre) são empreendimentos fundamentais na criação da ideia de uma nação, de uma tradição (Said, 1995, p. 13). Inventar um país como lugar de pertencimento é a primeira tarefa a que se lançam os escritores angolanos em sua luta de libertação. O resultado disso é a construção, em conjunto, de um sujeito e de uma nação pós-coloniais, ambos sendo inventados e narrados na literatura. Distanciados deste primeiro momento de invenção do país ( $O$ cão e os caluandas é publicado pela primeira vez em 1985, e Bom dia camaradas, em 2003), Pepetela e Ondjaki realizam, cada um em seu momento e à sua maneira, um percurso de 
retorno aos primeiros momentos pós-coloniais, e leem nos sinais visíveis, "na pele" da cidade de Luanda, suas contradições, que então já se anunciavam, sem deixar de celebrar a memória de um tempo cheio de promessas, um tempo, como diz Ana Paula Tavares, em que "ainda não se cuidava da memória porque a terra farta, gorda, prometia e todos os dias os sonhos que morriam renasciam das cinzas junto aos caminhos antigos" (Tavares, 2004, p. 42).

O tom crítico se acentua, e chega ao desencanto, em muitas narrativas que se dedicam a representar os tempos de guerra que dominaram o país nas décadas seguintes à independência. $O$ projeto de nação se esvazia consideravelmente; a guerra e o sofrimento constantes colocam em xeque as ideologias que sustentavam a ideia do país independente, expõem as feridas deste projeto, ao mesmo tempo em que se começam a problematizar os referenciais eurocêntricos a partir dos quais a própria noção de país foi forjada, no passado, pelo colonialismo europeu. Para além das fronteiras nacionais, autores como Ana Paula Tavares e Ondjaki inscrevem, no espaço morto da guerra, o imperativo da sobrevivência e da invenção de novas razões para narrar e existir.

No conto "Receita para ultrapassar os domingos", Ana Paula Tavares nos propõe, como o próprio título sugere, uma receita para curar as feridas da morte recente, uma espécie de ritual que parece obedecer a preceitos muito antigos, ancorados na tradição das avós, para atuar como um bálsamo sobre os destroços da guerra:

Arruma o quarto, varrendo as cinzas da véspera, e não te esqueças de guardar a última brasa para que possa ficar a arder o alecrim, o eucalipto (que ainda guardas de um outro tempo no Huambo), os cheiros misturados da avó Xiquinha e um pouco de açúcar masacavado. O fumo e o pequeno som das folhas a crepitar na pá de zinco farão mais leve a saudade (Tavares, 2004, p. 37-38).

O convalescente que se quer curar, além do próprio sujeito, é o espaço público da cidade, essa Luanda que, segundo a narradora, "anda perdida de si mesma" (p. 38). Na geografia da cidade, lemos as marcas deixadas pela ação devastadora, que se imprime como marca indelével:

A propósito, evita, quando desceres, o Kinaxixi. Não se trata de um problema de sereias, esses seres nem machos nem fêmeas que o habitaram outrora. O problema tem a ver com pássaros que fugiram quase todos e foram inventar silêncio para outros cantos do mundo. Os que ficaram estão enredados nos limos do tempo e fabricam ninhos de seiva, na esperança de não morrerem. Não têm tempo para ti (Tavares, 2004, p. 38-39).

Afugentar os fantasmas e acordar os vivos é tarefa para depois da morte. Lembrando a lição de Aristóteles, podemos dizer que, ao aliar as tarefas da historiadora que rememora o fato, com a da poetisa que registra o que poderia ter acontecido, a autora projeta um terceiro tempo ficcional, que consiste naquele que poderá vir a acontecer.

E é a partir do seu lugar no mundo, tomando como impulso a sua íntima relação com a cidade que se vê presa em um esquecimento que nela se 
instalou "e a trata mal", que a narradora faz de seu texto uma "receita" para renascer das cinzas da guerra e da devastação:

Por isso desce e procura as palmeiras. (...) Terás assim que visitar a ilha. Procura os antigos caminhos da água onde ainda podes ver barcos a dormir (...) Descobre as marcas dos pés da noite e segue pelas rotas de seda para ver aonde te conduzem. (...) Depois, e de alma lavada, podes voltar para casa. (...) Todo o domingo passará por ti sem que o pressintas enquanto, na pá de zinco, alecrim, eucalipto, açúcar mascavado e as horas se vão consumir lentamente (Tavares, 2004, p. 39-40)

O espaço devastado pela guerra, apresentado por Ana Paula Tavares, encontra representações ainda mais agonísticas, como em "Kuíto (três faces)", de Ondjaki (2004, p. 91-102). O conto inicia com uma epígrafe de Mia Couto, que nos instala já de saída no clima absolutamente sombrio que dominará a narrativa: "A guerra instala o ciclo do sangue. Passamos a dizer: 'antes da guerra, depois da guerra'. A guerra engole os mortos e devora os sobreviventes" (apud Ondjaki, 2004, p. 91). De fato, o conto de Ondjaki, seguindo o rumo da epígrafe escolhida, nos apresenta uma estrutura circular, em que mortos e sobreviventes se sucedem, sem que se possam vislumbrar contornos definidos entre vida e morte, sobrevivência e catástrofe. Considerada uma das cidades que sofreram de forma mais violenta o impacto da guerra, Kuíto nos é mostrada como um cenário de desolação: "As pessoas tinham, por toda a parte, sido substituídas pelos cães e pelas suas tristes sombras. A guerra tinha multiplicado desde início os corpos fedorentos que descansavam ao ar livre sem ninguém para os enterrar" (Ondjaki, 2004, p. 91). Cercados pela morte, os sobreviventes tentam, sem forças, reiniciar a vida, reverenciar seus mortos, superar a dor incurável e a culpa por terem sobrevivido, até o limite em que os mortos se compadecem dos vivos: "Com o tempo, ou melhor, com a morte, os mortos foram ficando mais calmos e decidiram-se, mais tarde, a partir em paz. Sem culpar aqueles vivos que ali tinham ficado, que agora seriam para sempre, sobreviventes" (Ondjaki, 2004, p. 98). O momento mais expressivo do conto se encontra em sua terceira parte, quando é relatada a história de Avô Bacate, preso numa cave para escapar à guerra, gulosamente acompanhado de boa quantidade de mantimentos, roubados das Forças Armadas. Isolado do mundo, de que ouve chegar tenuemente os ruídos dos tiros, ele vê se dissiparem "todos os prazeres": "os normais, os pequenos, os últimos até" (p. 99). Finalmente, após deixar-se consumir no esquecimento e na solidão da cave, Avô Bacate entregase à morte, murmurando "com uma voz pequena 'Ai mãe, sou tão infeliz..." (p. 102). A agonia de Kuíto, sintetizada na figura do Avô Bacate, nos traz a representação dos sujeitos pós-coloniais que sobrevive num espaço problemático, o do país mergulhado no contexto da guerra. Sobreviver, neste caso, é uma tarefa voltada para a reinvenção do pertencimento, saltando por cima de fronteiras, e revendo criticamente um projeto ideologicamente superado de nação.

É nesse sentido que podemos interpretar o discurso do narrador em "Não há mais lugar de origem", de José Eduardo Agualusa (2002, p. 61-63), como representante da vOz de um sujeito pós-colonial desterritorializado, um sujeito, conforme a formulação de Edward Said, "entre mundos" (Said, 2003, p. 301-315), já que não se prende mais a fronteiras nacionais, e se percebe como um sujeito cuja errância, num mundo que é inteiramente pós-colonial, 
reinventa pertencimentos e exige uma constante tarefa de tradução. Não é outro o sentido da evocação, pelo narrador, da dupla de cantoras brasileiras radicadas na Alemanha, e de sua canção, que diz: "Não há mais lugar de origem / a origem é existir / não me diga de onde eu sou / eu sou, não sou, eu estou aqui" (Agualusa, 2002, p. 61).

Com efeito, o sujeito pós-colonial que nos fala no conto de Agualusa se percebe como um tradutor dos diferentes significados históricos, políticos, raciais, étnicos e de gênero, dos diferentes modos de se vivenciar os desdobramentos da experiência colonial. Por isso afirma não haver mais lugar de origem - apenas lugares, provisórios, de identidade (tradutor, traidor?). O sonho que nos relata diz bem deste movimento de diluição das identidades, de indagação dos lugares, em que questões como nacionalidade, raça e etnia estão sendo constantemente postas em questão: "Adormeci e sonhei que viajava num comboio com destino a Berlim. Atravessávamos uma extensa paisagem de arvoredo húmido. Ao meu lado um homem mudava de raça, como um camaleão, consoante na carruagem estivessem sobretudo brancos, negros, chineses, ou indianos" (p. 62). Os temas do comboio em viagem, do personagem-camaleão que muda constantemente de cor num ambiente declaradamente multicultural, indicam de forma visível o cenário pós-colonial em que, conforme Stuart Hall (2003, p. 45), o processo de pluralização das identidades culturais desafia os nacionalismos e as fixações identitárias. Neste contexto, ainda segundo Hall (2003, p. 108-109), a perspectiva dualista do tipo aqui / lá, antes / agora, em casa / no estrangeiro se rompe, e o sujeito se mostra duplamente inscrito, aqui e lá, em casa e no estrangeiro, antes e agora, tudo ao mesmo tempo.

A condição pós-colonial encontra sua mais expressiva representação, no conto de Agualusa, através da personagem Raquel, sobre quem o narrador nos diz: "Naquela casa tudo parecia tocado pela solidão. Raquel tinha-me mostrado alguns discos de música angolana, velhos discos de vinil, do princípio dos anos 70" (p. 63). A imagem da personagem a dançar um merengue na solidão do apartamento nas manhãs de domingo ("há vinte anos que ninguém em Angola dança merengue"...) nos sugere a própria encarnação do exilado, sujeito fora de lugar, sem lugar. "Fronteiras Perdidas", nome que dá título ao livro de Agualusa, era como chamavam Raquel em sua infância: "os meninos, na escola, chamavam-me Fronteiras Perdidas, porque em certos dias eu parecia mulata, e noutros acordava com cara de branca. Acho que essa alcunha marcou o meu destino" (p. 63). E não seriam, pergunto agora, as "fronteiras perdidas" uma espécie de síntese da condição pós-colonial contemporânea? Se no nacionalismo pós-independência, foi importante e necessária a reivindicação de uma identidade para instrumentalizar a luta anticolonial e definir os contornos e referenciais políticos dos países emergentes, no momento pós-colonial, pósguerras, percebemos a constatação da crise de referências identitárias tais como fronteiras, nação, pertencimento. Não haverá mais, de fato, o lugar de origem?

E qual o lugar de um sujeito cuja "origem" se enfraquece até o risco do esvaecimento? Onde reinventar questões ainda significativas como pertencimento, vínculo, futuro?

Ao discutir a literatura africana contemporânea, que considera pósrealista, pós-nativista e transnacional, Kwame Anthony Appiah (1997, p. 216) identifica nessa literatura uma atitude de contestação das narrativas legitimadoras do Ocidente moderno, em nome de um humanismo - provisório e contingente, mas necessário (p. 218). Através de sua escrita, Appiah acredita que os romancistas contemporâneos da África pós-colonial estão buscando a superação de sua condição de Outro, recusando-se a ser as "máquinas de 
alteridade" inventadas pelo colonialismo e pela mercadologização de um mundo pós/neocolonial. Appiah aposta nas relações transnacionais para superação dessa condição de alteridade, superando o nativismo que celebrava e fixava as origens, étnicas, raciais e nacionais (p. 218-219).

Em sentido semelhante, Boaventura de Sousa Santos (2004) investe na proposta de um "pós-colonialismo de oposição", que seja ao mesmo tempo desterritorializado - por se basear na tradução de diferentes projetos parciais de emancipação social - e situado, uma vez que a tarefa da tradução busca definir contornos identitários para o sujeito pós-colonial localizado num território específico, ou seja, aquele advindo da experiência colonial portuguesa.

Já Stuart Hall (2003, p. 41) percebe a cultura contemporânea como essencialmente diaspórica. Nela, a África pós-colonial atua como metáfora das histórias suprimidas, das rotas culturais fragmentadas, das genealogias apagadas (p. 41-42). Para o autor, a perspectiva aberta para o sujeito pós-colonial aponta para a superação dos "modelos fechados, unitários e homogêneos de "pertencimento cultural", em direção a "processos mais amplos - o jogo da semelhança e da diferença - que estão transformando a cultura no mundo inteiro" (p. 47).

A partir das proposições desse conjunto de autores - e certamente de muitos outros que aqui não foram abordados -, podemos começar a formular, e quem sabe responder, a algumas das questões que tanto nos mobilizam: quem é, afinal, o sujeito pós-colonial nas culturas africanas de língua portuguesa, e qual o seu lugar na cena contemporânea.

\section{REFERÊNCIAS BIBLIOGRÁFICAS}

AGUALUSA, José Eduardo. Fronteiras perdidas; contos para viajar. 3. ed. Lisboa: Dom Quixote, 2002.

ANDERSON, Benedict. Comunidades imaginadas: reflexões sobre a origem e a difusão do nacionalismo. São Paulo: Companhia das Letras, 2008. (2008

APPIAH, Kwame Anthony. Na casa de meu pai; a África na filosofia da cultura. Rio de Janeiro: Contraponto, 1997.

ASHCROFT, Bill; GRIFFITHS, Gareth; TIFFIN, Helen. Post-Colonial Studies: the key concepts. London and New York: Routledge, 2005.

HALL, Stuart. Da diáspora; identidades e mediações culturais. Belo Horizonte: Editora UFMG; Brasília: Representação da UNESCO no Brasil, 2003.

HOBSBAWM, Eric. Nations and nationalism since 1780. Cambridge: Cambridge Ed., 2000.

LOOMBA, Ania. Colonialism/Postcolonialism. London and New York: Routledge, 1998.

ONDJAKI. Bom dia camaradas. Lisboa: Caminho, 2003. . Momentos de aqui. 2. ed. Lisboa: Caminho, 2004.

PEPETELA. O cão e os caluandas. 5. ed. Lisboa: Dom Quixote, 2002.

SAID, Edward W. Cultura e imperialismo. São Paulo: Companhia das Letras, 1995.

Reflexões sobre o exílio e outros ensaios. São Paulo: Companhia das Letras, 2003.

SANTOS, Boaventura de Sousa. "Do pós-moderno ao pós-colonial. E para além de um e outro". Conferência de Abertura do VIII Congresso LusoAfro-Brasileiro de Ciências Sociais, realizado em Coimbra, de 16 a 18 de setembro de 2004. Disponível em: www.ces.uc.pt 
SHOHAT, Ella. "Feminismo fora do centro". Revista Estudos Feministas, v. 9, n. 1, p. 147-163, 2001. Entrevista concedida a Sônia Maluf e Claudia de Lima Costa.

"A vinda para a América: reflexões sobre perda de cabelos e de memória". Revista Estudos Feministas, v. 10, n. 1, p. 99-117, 2002.

TAVARES, Ana Paula. A cabeça de Salomé. Lisboa: Caminho, 2004.

VIEIRA, José Luandino. Lunanda. Lisboa: Caminho, 2004. . A cidade e a infância. São Paulo: Companhia das Letras, 2007. 